
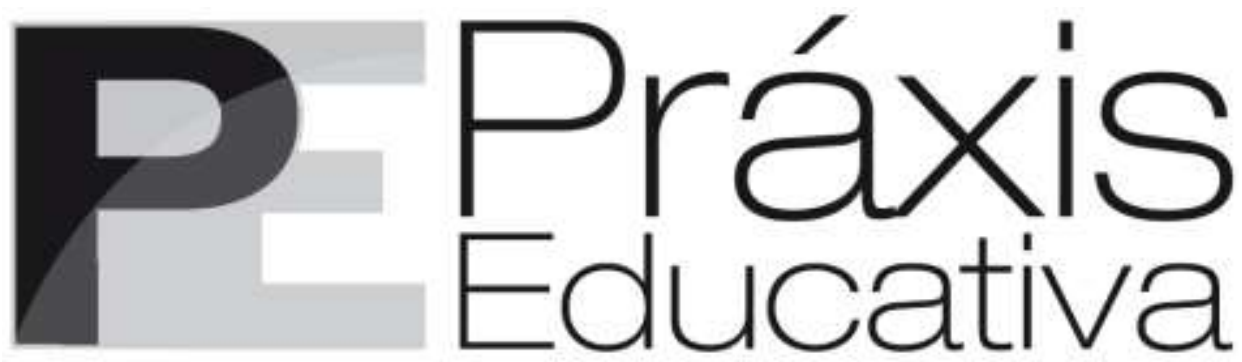

ISSN 1809-4031

elSSN 1809-4309

https://doi.org/10.5212/PraxEduc.v.17.19574.016

Dossiê: Relações étnico-raciais: práticas e reflexões pedagógicas em contextos, espacos e tempos

O processo de orientação como estratégia de superação do racismo institucional: relatos de um encontro ancestral em um contexto de PósGraduação de um Instituto Federal ${ }^{*}$

The orientation process as a strategy to overcome institutional racism: reports of an ancestral encounter in a Graduate Studies context at a Federal Institute

El proceso de orientación como estrategia para superar el racismo institucional: relatos de un encuentro ancestral en un contexto de Posgrado de un Instituto Federal

\author{
Bianca Barreto do Nascimento \\ (D) https://orcid.org/0000-0002-1832-5722 \\ Mariana Fernandes dos Santos ${ }^{* * *}$ \\ iD https://orcid.org/0000-0003-2296-3767
}

\begin{abstract}
Resumo: Neste trabalho, apresentamos uma discussão sobre a questão da relação entre orientanda/o e orientador/a nos processos de orientação no contexto de um curso de Mestrado. A encruzilhada deste texto é, por um lado, tratar sobre as tensões e as violências que ocorrem nessas relações, caracterizando-se, muitas vezes, como manifestações de racismos. Por outro lado, tratamos também sobre a possibilidade de essa relação reconfigurar espaços de cura e de parcerias científico-afetivas. Mobilizamos caminhos metodológicos que aquilombam resultados de estudos, de reflexões e de escrevivências, que apontam para a importância de tensionar epistemologias e comportamentos colonialistas pautados na perspectiva cientificista ocidental, de pensar o contexto acadêmico para que as relações de orientação possam caminhar para referências mais humanizadas e (re)encontros ancestrais.

Palavras-chave: Racismos. Orientação. Decolonialidades.
\end{abstract}

\footnotetext{
* Este artigo atendeu aos procedimentos éticos de pesquisa, apresentados em projeto submetido ao CEP do IFBA. Número do CAAE: 43232620700005031.

** Docente da Rede Municipal de Educação de São Francisco do Conde/Bahia. Mestra em Educação Profissional e Tecnológica. E-mail: <biabarfitness@gmail.com>.

*** Docente do Instituto Federal de Educação, Ciência e Tecnologia da Bahia (IFBA). Doutora em Ensino, Filosofia e História da Ciências. E-mail: <mariana.santos@ifba.edu.br>.
} 
O processo de orientação como estratégia de superação do racismo institucional...

\begin{abstract}
In this work, we present a discussion on the issue of the relationship between the mentee/the mentor in the guidance processes in the context of a Master's course. On the one hand, the crossroads of this text is to address the tensions and violence that occur in these relationships, often characterized as manifestations of racism. On the other hand, we also address the possibility of this relationship to reconfigure healing spaces and scientific-affective partnerships. We mobilize methodological paths that combine the results of studies, reflections and escrevivencias, which point to the importance of tensioning colonialist epistemologies and behaviors based on the western scientific perspective of thinking about the academic context so that orientation relationships can move towards more humanized references and ancestral encounters.
\end{abstract}

Keywords: Racisms. Guidance. Decolonialities.

Resumen: En este trabajo, presentamos una discusión sobre el tema de la relación entre el mentoreado y el instructor en los procesos de orientación en el contexto de un curso de Maestría. La encrucijada de este texto es, por un lado, tratar sobre las tensiones y la violencia que ocurren en estas relaciones, caracterizándose muchas veces como manifestaciones de racismos. Por otro lado, también abordamos la posibilidad de que esta relación reconfigure espacios de cura y de asociaciones científico-afectivas. Movilizamos caminos metodológicos que agrupan resultados de estudios, reflexiones y escrevivências, que apuntan a la importancia de tensionar epistemologías y comportamientos colonialistas pautados en la perspectiva científica occidental, de pensar en el contexto académico para que las relaciones de orientación puedan caminar hacia referencias más humanizadas y (re)encuentros ancestrales.

Palabras clave: Racismos. Orientación. Descolonialidades.

\title{
Para início de conversa
}

Nas palavras de Felipe Coelho (2019), indígena Tapuya-Kariri, quando as chamadas minorias sociais pensam em adentrar a universidade, logo vem em nossa memória algo erudito e difícil. Para o autor, toda essa imagem criada em torno da academia é a essência da colonização. "Aquilo que "conhecemos" na universidade, as formas de se abordar o mundo são todas convencionadas por normas, cristalizadas em uma tradição acadêmica que forja uma fôrma "clássica" de se fazer ciência, de se pensar e de produzir conhecimento" (COELHO, 2019, p. 49). A partir dessas provocações/problematizações, apresentamos a nossa escrita, que tem um movimento entre vozes das duas autoras e de outras pessoas que construíram, em coletivo, as discussões aqui mobilizadas, as quais tratam dos processos de normatizações ocidentais das instituições de ensino de Graduação e de Pós-Gradução ${ }^{1}$, com foco aqui na Pós-Graduação stricto sensu, em nível de Mestrado, no Instituto Federal de Educação, Ciência e Tecnologia da Bahia (IFBA), no contexto do Mestrado Profissional em rede - Programa de Pós-Graduação em Educação Profissional e Tecnológica (PROFEPT), no que tange às tensões, às violências e às reconfigurações a partir da decolonialidade das relações e dos processos de orientação.

Aqui, teorizamos e refletimos sobre vidas e existências em meio a situações adversas e utilizamos as metodologias das narrativas e histórias de vida que Carolina Maria de Jesus (2014),

\footnotetext{
1 Preferimos usar o termo “instituições de Graduação e de Pós-Graduação” em vez de Instituição de Ensino Superior por entendermos que esse termo se constitui na lógica ocidental e hierárquica, que supervaloriza esse espaço acadêmico em detrimento de outros, como, por exemplo, a Educação Básica, ou mesmo os que não são escolarizados. A nossa defesa é que os espaços sejam demarcados diante de suas características e de seus objetivos, e não hierarquizados.
}

Práxis Educativa, Ponta Grossa, v. 17, 2219574, p. 1-20, 2022 Disponível em: <https:// revistas2.uepg.br/index.php/praxiseducativa $>$ 
em Quarto de Despejo, nos ensinou a fazer. Uma metodologia que rompe as barreiras coloniais e que por costume é pouco aceita nos espaços acadêmicos, já que as concepções de ciência, educação, ensino, pesquisa, processo de orientação e metodologias que imperam nos espaços acadêmicos, como bem nos lembra bell hooks (2013), é de caráter elitista e colonial, alicerçadas pela supremacia branca e patriarcalista. Por conta disso, são excludentes e categorizam as pessoas que subvertem a esse padrão, como não dignas de poderem permanecer ou até mesmo de entrarem nesses espaços.

Em uma abordagem inicial, orientar é o ato de mostrar a direção. Dirigir, guiar, encaminhar, todas essas expressões são similares em termos de sentido e podem substituir o termo "orientar", como sinônimos. O processo de orientação em ambientes acadêmicos, por sua vez, é singular, e está mais relacionado ao ato de acompanhar, já que tende a desenvolver o tema de pesquisa, refinar a metodologia e contribuir com todo o trajeto de estudo, desde a proposta de pesquisa até a defesa de dissertação ou de tese. Quanto a isso, Freitas (2012) afirma que orientador/a é aquele/a que acompanha os passos de sua/seu orientanda/o. A orientação acadêmica abrange essa e outras tarefas, porém nem sempre é essa a compreensão de muitas/os professoras/es de Pós-Graduação.

Uma busca rápida pelas plataformas de pesquisa na Internet, em site de busca, acerca da temática "problemas com a orientação de mestrado", remete a aproximadamente 56.200.000 resultados em 0,53 segundos, dados que oscilam a cada busca para maior recorrência. Analisando superficialmente, esse pode ser um resultado que gere estranheza e desconforto, mas, infelizmente, trata-se de uma problemática mais comum do que se imagina, a qual vem ganhando visibilidade contemporaneamente. Tal constatação demonstra maior acirramento dos debates acerca dos processos de orientação, que se deu a partir das modificações nas regras de avaliação e de financiamento estabelecidas pela Coordenação de Aperfeiçoamento de Pessoal de Nível Superior e pelo Conselho Nacional de Desenvolvimento Científico e Tecnológico (Capes/CNPq). Desde meados da década de 1990, entre outras medidas, a Capes/CNPq reduziu os prazos para a conclusão do Mestrado e do Doutorado, para 24 e 48 meses, respectivamente, e as análises do desempenho dos Programas passaram a ser traduzidas em notas, instrumentalizando, assim, os financiamentos de estudos/pesquisas.

A aplicação do complexo instrumento de avaliação de programas - Datacapes/Coletacapes, criada para reunir informações sobre os Programas de Pós-Graduação stricto sensu do País e subsidiar o processo avaliativo da Capes, assim como os programas de fomento e de planejamento de políticas institucionais, desencadeou críticas, confrontando as disposições legais. Com esse feito, tais avaliações passam a apontar para a importância do/da orientador/a, cuja responsabilidade aumenta, impulsionando sua atividade a transcender os limites da relação orientador/aorientanda/o/s, para assumir proporções e importância institucionais.

Diversos são os casos em que os/as professores/as parecem acreditar que deixar o/a estudante sozinho/a vai auxiliá-lo/a no seu processo de construção de autonomia. Nesse sentido, Alves, Espíndola e Bianchetti (2012) salientam que dar autonomia aos/às alunos/as não significa distanciar-se deles/as, ou seja, não acompanhar a/o orientanda/o no desempenho das atividades acadêmicas, na escolha das disciplinas a serem cursadas e na preparação do trabalho final, por exemplo. Compreensões dessa natureza podem gerar nas/nos orientandas/os sentimentos de insegurança, angústia e impotência e até promover uma evasão - o que, por muito pouco, não aconteceu com a primeira autora deste texto, em um processo formativo de Mestrado.

Quanto a isso, Berndt (2003), ao pesquisar estudantes desistentes de Mestrado e de Doutorado em Administração de duas universidades paulistanas, constatou que uma das razões mais significativas do abandono dos cursos, mesmo já com créditos concluídos, deveu-se a problemas relacionados à orientação. Segundo relatos dos/das alunos/as, tais fatores foram a falta de uma orientação mais efetiva da dissertação ou da tese (14\%); a falta de tempo, de conhecimento,

Práxis Educativa, Ponta Grossa, v. 17, 2219574, p. 1-20, 2022

Disponível em: <https:// revistas2.uepg.br/index.php/praxiseducativa> 
O processo de orientação como estratégia de superação do racismo institucional...

de didática e de dedicação dos/as professores/as ao Programa de Pós-Graduação (12\%); e melhor organização dos horários de aulas e de encontros com os/as orientadores/as (23\%). Entretanto, para além das variáveis que determinam a dificuldade em encontrar um/uma orientador/a, vivenciei (primeira autora) também questões típicas do racismo estrutural, que se reflete no racismo institucional quando tenta hierarquizar a importância dos saberes e das temáticas relevantes para se trabalhar em um programa de Mestrado.

O racismo é a denominação da discriminação e do preconceito - direta ou indiretamente contra indivíduos ou grupos por causa de sua etnia, raça ou cor. É importante ressaltarmos que o preconceito é uma forma de conceito ou juízo formulado sem qualquer conhecimento prévio do assunto tratado, enquanto a discriminação é o ato de separar, de excluir ou de diferenciar pessoas ou objetos. Por definição, é entendido como crenças, atitudes e conformações institucionais que tendem a subjugar e a excluir grupos e pessoas em virtude de caracteres fenotípicos e/ou afiliação étnica, de acordo com Clark et al. (1999).

Corroborando Lima e Vala (2004), é possível afirmarmos que o racismo envolve uma rede ampla de aspectos para sua caracterização: é um processo de hierarquização, de discriminação e de exclusão de um grupo, ou mesmo um componente deste, que é distinto dos demais por possuir alguma marca física externa - real ou imaginária - que, no olhar do outro, associa-se a alguma característica subjetiva. É o que Oracy Nogueira (2006) denomina de preconceito de marca e preconceito de origem. Para o autor, quando o preconceito de raça se exerce em relação à aparência, ou seja, quando toma por pretexto, para as suas manifestações, os traços físicos do indivíduo, a fisionomia (como cabelo, nariz etc.), os gestos, o sotaque, diz-se que é de marca; quando basta a suposição de que o indivíduo descende de certo grupo étnico para que sofra as consequências do preconceito, diz-se que é de origem.

Nessa esteira, o racismo, que é estrutural em nossa sociedade, reforça o fato de que existem sociedades estruturadas com base na discriminação que privilegia algumas raças em detrimento das outras. Ela ocorre muitas vezes de forma velada, e, por vezes, imperceptível, mas sempre violenta, uma forma de racismo que tende a ser mais perigosa exatamente por ser de difícil percepção. Tratase de um conjunto de práticas, de hábitos, de situações e de falas recorrentes em nossos costumes e que promovem, direta ou indiretamente, a segregação ou o preconceito racial. Chamamos de estrutural por compreendermos que há uma estrutura social que possibilita a manutenção do racismo ao longo da história, inclusive do Brasil, que pode ser contada a partir das próprias leis do país - desde as que são da época em que as pessoas negras eram escravizadas, é óbvio, mas outras vieram depois da abolição.

Em se tratando da Lei Áurea, por exemplo, de 1888, é importante ressaltarmos que a famigerada signatária da lei, a Princesa Isabel, não a assinou por compreender a necessidade da abolição, mas, sim, por interesses políticos coloniais. É importante e necessário dizermos sobre isso para desmistificar a ideia de bondade e de sensatez que pairou sobre a história da princesa branca por muito tempo! Além de o Brasil ter sido o último país das Américas a aderir à libertação das pessoas escravizadas, parte da população negra que ainda vivia em condições escravizatórias no país se "viu livre" e à margem da sociedade, já que não havia opções de emprego, saúde ou educação. Nesse sentido, cabe atentarmos para a realidade da Educação Profissional no Brasil que possui seu marco de criação no Decreto No 7.566, de 23 de setembro de 1909, do Presidente Nilo Peçanha, garantindo o surgimento da Escola de Aprendizes e Artífices da Bahia em 1909 (BRASIL, 1909), no intuito assistencialista de retirar das ruas os pobres e desvalidos, a partir da profissionalização, com uma concepção de educação essencialista. Podemos ler a seguir:

Práxis Educativa, Ponta Grossa, v. 17, 2219574, p. 1-20, 2022

Disponível em: <https://revistas2.uepg.br/index.php/praxiseducativa> 
Considerando: que o aumento constante da população das cidades exige que se facilite às classes proletárias os meios de vencer as dificuldades sempre crescentes da luta pela existência; que para isso se torna necessário, não só habilitar os filhos dos desfavorecidos da fortuna com o indispensável preparo técnico e intelectual, como fazê-los adquirir hábitos de trabalho profícuo, que os afastará da ociosidade ignorante, escola do vício e do crime: que é um dos primeiros deveres do Governo da República formar cidadãos úteis à Nação. (BRASIL, 1909, n.p.).

Se atentarmos para o fato de que esse feito ocorreu em uma conjuntura de duas décadas após a abolição, facilmente caracterizaremos (ponderando inclusive os riscos de configurarmos estereótipos, mas tendo referência o racismo que estrutura a nossa sociedade) a população que ocupava o lugar de "pobres e desvalidos que habitavam as ruas" naquele período, sobretudo no contexto baiano, diante da imigração escravocrata. Dessa forma, é necessário compreendermos que os reflexos desses feitos repercutem até os dias atuais, reiterando a importância de debruçarmonos a cada dia com mais afinco em estudos voltados para essa temática, inclusive no âmbito da Pós-Graduação, que carrega consigo os desdobramentos do racismo estrutural convertidos em institucional.

No que se refere ao racismo institucional, de maneira menos direta, é a manifestação de preconceito por parte de instituições públicas ou privadas, do Estado e das leis que, de forma indireta, promovem a exclusão ou o preconceito racial. Como exemplo óbvio, é possível citar as formas de abordagem de forças policiais contra negro/a/s, que tendem a ser mais agressivas, bem como a maneira como o conhecimento produzido por negras e negros ao longo da história foi silenciado nos livros e nos conteúdos escolares - o epistemicídio da cultura negra. Ainda sobre isso, Sueli Carneiro (2005) observa que esse apagamento de epistemologias africanas se integra ao dispositivo da racialidade por conter em si características de anulação.

É através desse operador que este dispositivo realiza as estratégias de inferiorização intelectual do negro ou sua anulação enquanto sujeito de conhecimento, ou seja, formas de sequestro, rebaixamento ou assassinato da razão. Ao mesmo tempo, e por outro lado, o faz enquanto consolida a supremacia intelectual da racialidade branca. (CARNEIRO, 2005, p. 10).

Ao ingressar na segunda turma do Mestrado Profissional em Educação Profissional e Tecnológica do IFBA (PROFEPT-IFBA), a primeira autora deu início a um novo ciclo de luta. E que luta! Assim como em todos os outros espaços acadêmicos, como mulher negra, teve de se apropriar de uma consistente base teórica para legitimar a relevância da pesquisa com temática relacionada às questões étnico-raciais. É incrível como nesses espaços o óbvio parece tão distante da realidade.

Quando se propôs a pesquisar o recorte que trata do racismo como determinante de saúde mental e emocional da mulher negra, estudante do curso de Refrigeração Industrial e Climatização no campus Salvador, já imaginava os diversos questionamentos que ouviria. Imaginava isso, pois, ao longo da sua trajetória, sempre foi comum ter de preparar-se para comprovar que estudos sobre raça, gênero e saúde possuem extrema relevância quando categorizados, mais ainda quando interseccionados. $\mathrm{O}$ que não fazia parte das suas expectativas nesse processo eram os entraves construídos pelo racismo estrutural e velados pela institucionalidade que encontraria. Contudo, não se pode negar a riqueza da experiência que se permitiu, hoje, junto a sua orientadora do período do Mestrado (segunda autora deste texto), escreviver e elucidar novos caminhos nas perspectivas de orientação acadêmica. 
O processo de orientação como estratégia de superação do racismo institucional...

\section{A pesquisa de Mestrado como ato político, social e de autocuidado: relatos e escrevivências ${ }^{2}$ de duas mulheres negras}

Durante as itinerâncias investigativas do Mestrado no Instituto Federal da Bahia, diversas foram as vezes que foi possível verificar a existência das intersecções de raça, de classe e de gênero no processo de orientação. Cursar o Mestrado Profissional fazia parte dos meus planos (primeira autora $)^{3}$ e, mesmo com as múltiplas atividades que exercia no período, inclusive a finalização da Pós-Graduação lato sensu na Universidade Federal da Bahia (UFBA), dediquei-me com afinco a essa formação. Coincidentemente ou não, um estágio curricular da Engenharia de Produção que cursava paralelamente como bolsista, em uma faculdade particular em Salvador, se alinhou ao período inicial do curso de Mestrado PROFEPT, e o contato direto com as estudantes e suas realidades dentro da instituição me fez refletir e revisitar, anos depois de ter concluído o curso técnico, os processos de dor e de sofrimento causados pela ausência do trato com a temática étnico-racial e de gênero, bem como pela falta de reconhecimento das interseccionalidades que permeiam a vida dos discentes dessa instituição.

Em um intervalo entre as aulas, horário de almoço, para além de espairecer e me preparar para as aulas do turno seguinte, pude presenciar a ação de uma das chapas do Grêmio Estudantil - Gestão Presente, ainda em período eleitoral. Os estudantes ocupavam a "Praça Vermelha", dispostos como se sentissem bem e utilizavam um microfone aberto para expressar seus sentimentos e sensações enquanto membros do IFBA: "Eu não dou conta?", "eu não consigo?", "era o sonho dos meus pais?", "são muitas disciplinas?", "eu venho de escola pública, como vou acompanhar o conteúdo aqui??", "eu disse 17 matérias! Viro várias noites estudando, mas, não dá?’ - os relatos ali eram similares. Diversas vozes negras ${ }^{5}$ ecoavam no sentido de afirmar suas experiências com as desigualdades e a ausência do trato específico com as questões étnico-raciais na Instituição, reiterando o quanto o processo de formação em uma escola técnica pode ser adoecedor. Entretanto, as falas ali presentes, também remetem ao construto histórico de constituição do Brasil, já que, em geral, a maioria delas refletem o sentimento de culpa e a incapacidade por parte dos estudantes.

Santos (2005) faz um resumo em um relatório mensal padronizado da Educafro, intitulado Sete atos oficiais que decretaram a marginalização do povo no Brasil. O primeiro ato considerado oficial é a implantação da escravidão no Brasil, deliberado a partir da bula Dum Diversas, na qual o Papa Nicolau declarou ao rei de Portugal em 1452:

\footnotetext{
[...] nós lhe concedemos, por estes presentes documentos, com nossa Autoridade Apostólica, plena e livre permissão de invadir, buscar, capturar e subjugar os sarracenos e pagãos e quaisquer outros incrédulos e inimigos de Cristo, onde quer que estejam, como também seus reinos, ducados, condados, principados e outras propriedades... e reduzir suas pessoas à perpétua escravidão, e apropriar e converter em seu uso e proveito e de seus sucessores, os reis de Portugal, em perpétuo, os supramencionados reinos, ducados, condados, principados e outras propriedades, possessões e bens semelhantes [...]. (SANTOS, 2005, p. 1).
}

\footnotetext{
${ }^{2}$ Conceito de Conceição Evaristo (ver EVARISTO, 2020).

${ }^{3}$ Fazemos a partir daqui um movimento de escrita que ora trará a narrativa em primeira pessoa do singular, quando as autoras falam de si, ora haverá a escrita na primeira pessoa do plural quando falamos de nós, autoras e outros sujeitos envolvidos no processo.

${ }^{4}$ Nome atribuído a uma praça dentro de um dos campi da instituição.

5 Afirmamos que são vozes negras com base na pesquisa de Mestrado que realizamos entre os anos de 2019 e 2021 no PROFEPT-IFBA, aprovada pelo Comité de Ética e Pesquisa do IFBA. A defesa da dissertação e do produto educacional ocorreu no ano de 2021.
}

Práxis Educativa, Ponta Grossa, v. 17, 2219574, p. 1-20, 2022 Disponível em: <https:// revistas2.uepg.br/index.php/praxiseducativa $>$ 
Pouco depois, em 1554, esses poderes foram estendidos aos reis da Espanha, e, apoiados nesse documento, deu-se início a uma devastação no continente africano, matando e escravizando milhões de habitantes. O segundo ato, por sua vez, está relacionado à Constituição de 1824. Tratase de uma Lei Complementar que dizia que a escola era um direito de todos os cidadãos, o que não incluía os povos escravizados, como aponta Chiavenato (1986), a população negra não poderia frequentar as escolas, já que, para as leias imperiais, ela era vista como transmissora de doenças contagiosas. Com isso, reitera-se a ideia de que os poderosos do Brasil sempre souberam que o acesso à educação é uma alavanca de ascensão social, econômica e política de um povo. Não por acaso, a Educação Pública segue sofrendo tentativas de sucateamento a partir das ações de corrupção e desvios de verbas noticiadas rotineiramente pela mídia.

O terceiro ato é a Lei de Terras, que, em 1850, permitiu ao Estado a venda de espaços agrários a custos altos. Para se ter uma ideia, nessa época, 350 anos após a invasão do Brasil, quase todo o litoral brasileiro estava povoado por Quilombos - formados por negros que, por meio de diferentes formas, conquistavam a liberdade e construíam uma forma alternativa de organização social, tendo tudo em comum. As sobras de produção eram vendidas aos brancos das vilas e, percebendo o crescimento do poder econômico do povo negro e a consequente diminuição da mão de obra escravizada para a produção, decretou-se a referida lei. Quanto a ela, Chiavenato (1986) pondera que, com a renovação da lei, as terras passaram a ser adquiridas por meio de compra por um valor muito alto; por conta disso, o trabalhador livre foi obrigado a permanecer nas terras, substituindo as pessoas escravizadas.

A guerra do Paraguai (1864-1870) é considerada o $4^{\circ}$ ato oficial, pois foi um dos instrumentos usados pelo poder para reduzir a população negra do Brasil. Foi difundido que todos os negros que fossem lutar na guerra, ao retornarem, receberiam a liberdade e os já livres receberiam terra. Caso a convocação fosse para o filho do fazendeiro, era comum escondê-lo e, em seu lugar, enviar de 5 a 10 negros. Com isso, a população negra do Brasil, que era de 2 milhões e 500 mil pessoas (45\% do total da população brasileira - depois da guerra, diminuiu para 1 milhão e 500 mil pessoas - 15\% do total da população brasileira, como afirma Viotté da Costa (1986)).

Em 1871, a Lei do Ventre Livre, vista por muitos, até hoje, como uma benfeitoria, dizia que toda criança que nascesse a partir daquela data nasceria livre. Na prática, essa lei se comportava como o $5^{\circ}$ ato oficial de marginalização do povo negro, pois objetivava desobrigar os senhores de fazendas de criar nossas crianças negras, pois, já com 12 anos de idade, poderiam sair para os quilombos à procura da liberdade negada nas senzalas. Com a determinação, surgiram os primeiros menores abandonados do Brasil. Em quase todas as igrejas do país, os padres tocaram os sinos aplaudindo a assinatura dessa lei, que separava as crianças de seus pais, desestruturando a família negra.

Ainda no caminho das falácias de benfeitorias, a Lei do Sexagenário de 1885, também é ensinada em diversas escolas como sendo um reconhecimento do senhor para com o "escravo que muito trabalhou". Segundo essa lei, que caracteriza o $6^{\circ}$ ato oficial de marginalização do povo negro, todo escravo que atingisse os 60 anos de idade ficaria automaticamente livre. A partir disso, questionamos: Quem conseguiria, em condições desumanas como as que viviam os escravizados, sobreviver por tanto tempo? $\mathrm{Na}$ verdade, essa foi a forma mais eficiente encontrada pelos opressores para abandonar nas ruas, os/as velhos/as doentes e impossibilitados/as de continuarem gerando riquezas, surgindo, assim, os/as primeiros/as mendigos/as nas ruas do Brasil, pessoas em situação de rua, e maioria negra.

Se, diante do exposto, ainda há quem cogite a ideia de que antes da abolição a legislação não tenha relação direta com o racismo, apresentamos o que Santos (2005) afirma ser o sétimo ato de marginalização do povo negro, em 1890. Com o crescimento da industrialização no país, após a

Práxis Educativa, Ponta Grossa, v. 17, 2219574, p. 1-20, 2022

Disponível em: <https:// revistas2.uepg.br/index.php/praxiseducativa> 
O processo de orientação como estratégia de superação do racismo institucional...

abolição, o governo atentou-se para o fato de que, se o povo negro ocupasse as vagas nas indústrias, poderia surgir uma classe média negra poderosa, o que colocaria em risco o processo higienista de embranquecimento do país. Como solução, decretou-se a reabertura do país às imigrações europeias, definindo que negros e asiáticos só poderiam ingressar no Brasil com autorização do congresso, conforme afirma Viotté da Costa (1986). Ocupando as vagas de emprego nas indústrias paulistas, os europeus pobres também foram utilizados para potencializar a marginalização do povo negro no Brasil.

O fato é que a primeira vez em que a legislação contribuiu, de fato, para a democracia racial no Brasil foi em 1989, quase um século depois da falácia da abolição, quando a Lei Caó tornou o racismo um crime inafiançável e imprescritível. Ainda assim, sustentando o mito da democracia racial a partir das ideias de miscigenação e de igualdade, o racismo estrutural e estruturante segue favorecendo os brancos em detrimento de negros e de indígenas, e as falas dos estudantes naquele momento, "na Praça Vermelha", reiteram o quanto isso é adoecedor.

Observando-os falar de si e ouvir os outros, rememorei a importância de compartilhar as dores para avançar. A minha conexão com as falas era tamanha que nem pude conter as lágrimas. Chorando, com um misto de pensamentos científicos, filosóficos e emotivos em mente, quando percebi, já estava ali, com o microfone na mão falando do quanto me via neles, mesmo tanto tempo depois de ter concluído o curso técnico. Recordo que, quando mencionei ter retornado ao IFBA como mestranda, a felicidade dos estudantes era visível. Parabenizei os envolvidos pela ação, falei da minha trajetória naquele espaço como mulher negra e do quanto teria sido válido um espaço como aquele há anos. Disse-lhes:

[...] dói demais ouvir vocês dizerem que não conseguem! Dói, porque eu também acreditei, até certo momento, que o problema estava em mim! Estava em mim por ser mulher num curso majoritariamente masculino, por ser negra e pobre num espaço ocupado por uma parcela significativa da elite branca da sociedade, por não aceitar um estágio em que eu atuaria como secretária ao invés de exercer a minha função como técnica para não "desconcentrar os funcionários" com as curvas do meu corpo. Independentemente de qual fosse o problema, ele estava em mim! Até que acumulando debates, leituras e muitas reflexões, eu parei de me culpar! Reconheci, com muito esforço, que o problema não era eu! E, acreditem, também não são vocês! É necessário repensar o processo de formação nesse Instituto, gente! Vocês acham o quê? Que nos cursos superiores isso muda? Que no Mestrado é diferente? Não! Não é. Mas, eu quero que saibam que vocês não estão sozinhos! E, se para a nossa dor deixar de ser vista como "mimimi" eles precisam de dados científicos? Não se preocupem! Vou me recompor, vou me organizar e, agora, mais do que nunca, tenho certeza do que vou pesquisar! (Relato da primeira autora).

Hoje, compreendo que revisitar esses lugares internos de sofrimento distante de um processo terapêutico não era o mais adequado. A pessoa que sofre pode prender-se à história vivida de tal forma que fica impedida de encontrar diferentes ângulos para encarar aquilo que viveu, criando um caminho sem saída no qual parece não haver possibilidades de cura. Em particular, a partir daí, busquei no processo de pesquisa a oportunidade de reorganizar as histórias e escrevivências que me levaram até ali, para romper com a estagnação que elas poderiam provocar. Depois desse dia, o projeto, que já estava encaminhado desde meados do primeiro semestre do curso de Mestrado, foi ganhando referencial teórico dia após dia. As experiências de racismo estrutural e institucional, por sua vez, foram tornando-se rotineiras no meu processo formativo.

Acerca do entendimento do racismo estrutural, é possível citar situações nas quais foi necessário, após a incessante busca por alguém que me orientasse, fazê-lo compreender a relevância da temática. Meu orientador seria, inicialmente, um homem socialmente branco, franciscano, sem nenhum acúmulo sobre a temática. Um professor que conheci em uma das disciplinas, na qual se 
comportou com muita firmeza e apresentando amplo domínio do conteúdo normativo relacionado à Língua Portuguesa.

A priori, a minha maior ressalva era ter um homem branco orientando uma pesquisa sobre mulher negra - podem me julgar, mas acredito que lugar de fala é de suma importância em pesquisas empíricas. No entanto, ainda com a ressalva, minha vontade era de pesquisar! Avançar! Ler, fichar, resumir, resenhar, escrever aos poucos a dissertação, mandar para o orientador, receber os arquivos cheios de correções, anotações e sugestões que pudessem enriquecer o trabalho, discutir os títulos das seções, analisar quais os autores que melhor dialogavam com o tema, corrigir, reenviar! Enfim, eu estava pronta para trabalhar no projeto. E, trabalhei - assim, conjugando o verbo na primeira pessoa do singular. Contudo, prática orientada não é uma "via de mão dupla"? No meu caso, tudo aquilo que dependia do "orientador" para acontecer simplesmente não acontecia.

Acerca da relevância da temática que gostaria de estudar, justificava exemplificando com ocasiões oriundas do racismo estrutural: a) em relação ao acesso de negros e de indígenas a locais que foram, por muito tempo, espaços exclusivos da elite econômica e racial branca, como universidades, podemos citar o número de negros que tinham acesso aos cursos superiores de Medicina no Brasil: antes das leis de cotas, era ínfimo, ao passo que a população negra estava relacionada, em sua maioria, à falta de acesso à escolaridade, à pobreza e à exclusão social; (b) falas e hábitos pejorativos incorporados ao nosso cotidiano tendem a reforçar essa forma de racismo, visto que promovem a exclusão e o preconceito mesmo que indiretamente - essa forma de racismo manifesta-se quando usamos expressões racistas, mesmo que por desconhecimento de sua origem, como a palavra "denegrir" com sentido de depreciar. ${ }^{6}$. Também acontece quando fazemos piadas que associam negros e indígenas a situações vexatórias, degradantes ou criminosas ou quando desconfiamos da índole de alguém por sua cor de pele ou tipo de cabelo.

Passado esse período de entendimento e compreensão da relevância da proposta de trabalho, não havia tempo para encontros presenciais e, quando conseguíamos alinhar, por vezes eu era surpreendida com a ausência repentina do indivíduo. Além dos diversos atestados e da indisponibilidade, havia ainda a dificuldade em realizar a leitura dos materiais enviados e as possíveis correções ou considerações acerca deles. Foram meses de pesquisa solitária que se aliaram a uma busca incansável por algum acadêmico que se disponibilizasse a realizar a orientação. Todo profissional que demonstrasse o mínimo de responsabilidade com a pesquisa científica recebia o meu convite: Aceita me orientar? É entristecedor lembrar que precisei passar por isso.

Apesar de pesquisar acerca da Saúde mental e emocional, sempre relutei em receber apoio psicológico, mas a angústia que sentia a essa altura me fez seguir o conselho de uma amiga: marcar a consulta - ainda que sem nenhuma pretensão de comparecer. No dia, desloquei-me com as ideias oscilando entre a necessidade de ir e a vontade de não ir para a tal terapia. No caminho até o consultório, também me questionei acerca da real necessidade de fazer isso. Até o horário agendado, já na sala de espera, eu ainda pensava: "Se o orientador mandar uma resposta, tá tudo certo! Nem entro na sala". Sem a resposta, entrei no consultório. Apresentei-me e falei do quanto estar ali me causava estranheza. Enquanto me apresentava, ela fazia algumas anotações. Em seguida, a profissional começou a fazer perguntas simples, a respeito do que teria me levado a procurá-la, se com a pouca idade que tinha já estava, segundo ela, tão bem-sucedida, fato não tão comum no histórico de jovens mulheres negras.

Em uma mistura de choro e riso, falei dessa situação de descaso, de como isso é naturalizado no processo de orientação acadêmica, do quanto isso exerce influência para que as pessoas

\footnotetext{
"O Movimento Negro tem ressignificado o vocábulo para o sentido de "tornar negro", algo bom e importante: "Vamos denegrir os espaços".
} 
O processo de orientação como estratégia de superação do racismo institucional...

busquem apenas títulos, desconsiderando, por vezes, a relação com o objeto de estudo e sua relevância para a sociedade. Eu estava indignada, ela calada. Continuei dizendo que essa talvez seja uma das causas do surgimento de tantas pesquisas científicas que só reproduzem o que já foi dito e questionei: "Como é que eu posso discutir racismo enquanto determinante de saúde mental e emocional da mulher negra estudante de Refrigeração e propor mudanças numa instituição, se o processo de pesquisa está sendo adoecedor?’’

Em silêncio, percebi que eu disse a ela boa parte do que gostaria de ter dito ao orientador. Ela permaneceu em silêncio por um tempo e, quando começou a falar, trouxe experiências da sua vida que se assemelhavam à situação que eu estava passando, e como isso havia afetado as ações dela como mulher. Assim, o que era terapia se transformou em uma conversa, uma troca riquíssima de relatos de dores, de saberes e de aprendizagens. Despedimo-nos, mas não garanti retornar.

Em meio ao ocorrido, fui embora com a certeza de que essa era uma problemática bem maior do que eu conseguia mensurar, e não vou negar o quanto me senti impotente. Naquele momento, estava disposta a trancar o curso. É uma situação que reflete o desrespeito para com o estudante, o sucateamento da educação pública e, principalmente, o racismo estrutural que permite tamanha hierarquização da importância dos saberes. Ainda assim, não posso deixar de agradecer aos que contribuíram de alguma forma para que não desistisse! Inclusive aos que receberam as versões de projeto de qualificação e corrigiram com afinco e rigor, oferecendo retorno sempre mais rápido do que o orientador, graças às Deusas. E foram muitos! Dos que ocupam atualmente cargos de gestão no IFBA, aos que nunca fizeram parte da Instituição. Gratidão!

Ao entrar em contato com o coordenador adjunto do Mestrado, conversei sobre a situação que já vinha relatando diariamente acerca das dificuldades em manter o processo de orientação e sinalizei o interesse em realizar o trancamento. Ele, também homem branco, foi muito solícito a ajudar. Disse compreender o meu descontentamento, mas reiterou a importância da pesquisa para o programa, solicitando que eu aguardasse a reunião do colegiado para decidir, sugerindo a troca de orientador após a qualificação.

Sem muitas esperanças, continuei me preparando e, quando o professor teve disponibilidade, solicitei um encontro para que pudesse apresentar os slides com a pesquisa a ele, na intenção de me preparar para a banca de qualificação - composta por duas mulheres negras que são referências em estudos étnico e raciais - uma professora que esteve comigo ao longo da graduação na UFBA e uma professora do IFBA. Com alguns desencontros, agendamos uma data para que eu apresentasse os slides. Preparei um protótipo do produto educacional em miniatura para que o orientador conhecesse a proposta de maneira mais realista e apresentei-o tentando cumprir o tempo estimado. Ao final, sinalizei que gostaria que a apresentação fosse aberta ao público e que entregaria algumas fichas de avaliação para que cada espectador pudesse se expressar e, por conseguinte, construir comigo a proposta de defesa. Ele me parabenizou mais uma vez pelo trabalho, pela leveza na escrita e solicitou que eu fizesse o convite às componentes da banca.

Ainda sem data determinada para a apresentação, em 29 de setembro de 2019, oficializei os convites para a composição da banca por e-mail, no qual anexei o projeto para que tivessem acesso com antecedência. A priori, formalizamos uma quarta feira, 20 de novembro para o evento. Entretanto, uma das componentes não tinha disponibilidade para essa data; assim, adiamos para a semana seguinte, 27 de novembro de 2019. Para mim, estava ótimo! Depois de tanta espera, era chegado o momento. Quarta-feira, dia de importantes ventos, uma hora antes do previsto para o início da apresentação eu já estava no IFBA, pedindo às Deusas que me permitissem qualificar em paz. Muito bem-vestida, em uma estampa africana que havia comprado em João Pessoa meses antes, durante as andanças da minha participação no Congresso Brasileiro de Pesquisadores/as 
Negros/as (COPENE) ${ }^{7}$ - a qual rendeu uma publicação sem orientação - lá estava eu, só para não perder o costume, esperando o orientador.

Sala 308, Bloco A e porta trancada. Uma das componentes da banca já aguardava no mesmo bloco e abriu a porta. Entrando, cadê o projetor? O notebook, eu sempre carregava comigo. Entrei em contato com o orientador para saber o que havia acontecido, e ele me respondeu que "achou que o coordenador do curso, que também estava na banca, levaria". Surtei? Não. Respirei e saí batendo de porta em porta nos setores desse pavilhão até encontrar alguém que pudesse me emprestar. Enquanto isso, a professora que abriu a porta e levou a turma na qual lecionaria naquela tarde para assistir à apresentação, estava tentando encontrar recursos para que eu pudesse criar um espaço minimamente organizado para a qualificação. Serei sempre grata.

Consegui o projetor e, nos corredores, ao retornar para a sala, encontrei o tão esperado orientador. Já nem conseguia trocar muitas palavras com ele. Durante a instalação do recurso audiovisual para apresentar, um dos cabos apresentou defeito. Saí novamente em busca de ajuda. Retornando, encontrei na sala mais uma componente da banca e uma grande amiga que havia convidado. Cumprimentei-as e já fui pedindo favores! À professora externa, pedi paciência para aguardar o orientador que já não estava ali. À amiga, pedi que providenciasse algumas garrafas de água mineral e biscoitinhos. Enquanto ela saiu para providenciar, continuei ornamentando a sala com a ajuda da professora do IFBA que, certamente, já havia notado meu desespero. Cedeu um quadro que estava no grupo de pesquisa do qual ela faz parte com a imagem de uma deusa de ébano para compor o espaço, alguns copos descartáveis, guardanapos, um tecido vermelho com o qual cobri a mesa e um aromatizador de ambientes. É surreal a força que nasce de mulheres negras organizadas. Em menos de uma hora, tudo que dependia de mim estava pronto para a apresentação. E o orientador?

Com a chegada dele e do coordenador, a banca estava composta e eu pronta para qualificar. Emocionada, saudei aos presentes, fiz uma breve apresentação, distribui as fichas de avaliação e pedi que fechassem os olhos. Quando o silêncio aconteceu, recitei parte do poema Gritaram-me Negra e chamei-os para a reflexão acerca do quão relevante é discutir essa temática. Pedindo que abrissem os olhos, iniciei a apresentação. Recordo-me da presença de diversas mulheres negras como espectadoras e do quanto seus olhares demonstravam admiração - representatividade importa! Pedi que o orientador passasse o protótipo do produto educacional entre os presentes para que facilitasse a compreensão. Finalizei com o outro trecho do poema que havia iniciado, recolhi as fichas de avaliação e agradeci citando a filosofia ubuntu - afinal, mais do que nunca, eu conhecia o sentido da expressão "eu sou porque nós somos!".

Sei que cheguei até ali por conta de uma autonomia que já havia desenvolvido, mas que nada tinha a ver com a situação de abandono que passei. No enfoque de Segre, Silva e Schranm (2005), autonomia é uma propriedade constitutiva do ser humano, na medida em que o indivíduo escolhe suas normas e seus valores, faz projetos, toma decisões e age em consequência dessas escolhas. Nesse sentido, se a ideia dele era dar liberdade para a orientanda exercer sua autonomia, houve um equívoco conceitual, de fato. Em perspectivas mais dialógicas como a freiriana, a autonomia é um ato político construído no coletivo, não é dada, mas é possível criar condições para seu desenvolvimento, um caminho entre liberdade e emancipação que está longe do deixar caminhar solitária/o.

\footnotetext{
7 O COPENE tem como objetivo geral reunir pesquisadores/as negros/as para discutir, apresentar, ampliar e avaliar as ações e as estratégias de combate ao racismo, às políticas públicas direcionadas à população negra brasileira e as produções científicas e acadêmicas.
} 
A fronteira entre liberdade e negligência é, de fato, muito tênue. Proporcionar um caminho acadêmico sem coerção, manipulação e autoritarismos, em que a/o orientanda/o viva e se desenvolva ao seu próprio ritmo, de acordo com as suas próprias motivações, seu grau de maturidade e suas capacidades físicas, mentais e emocionais, é uma proposta maravilhosa. No entanto, os inúmeros relatos trazidos ao longo do texto aproximam-se mais do ideal de abandono e de negligência, e, em nossa concepção, o que ele tinha feito até ali foi precarizar o processo de construção da pesquisa. Diante do exposto e dada a importância dessa relação, uma das providências possíveis de serem tomadas por universidades e institutos de pesquisa que abrigam estudantes e orientadores/as é preparar seus/suas docentes para lidar com as/os orientandas/os, assim como garantir também sobre a função das orientadas/os no processo.

O orientador - aquele mesmo, que nunca orientou - entregou uma carta na reunião de colegiado solicitando a saída do programa de Mestrado, pedindo que os colegas acolhessem suas/seus orientandas/os. Isso mesmo! Agora, era oficial. Eu estava sem orientador. Naquele momento, era eu e a minha dor. Havia um nó na minha garganta. Uma vontade de gritar. Desaguei em lágrimas e questionamentos que pareciam sem resposta.

Eu não estou conseguindo mais, eu estou no meu limite! Eu estou analisando documento,
construindo questionário, mas sem orientação é complicado. E, aí, eu preciso de um
posicionamento da coordenação o mais rápido possível. Inclusive, se houver possibilidade,
eu estou pensando em dar uma trancada porque está sendo muito cansativo pra mim, assim.
Dá conta das coisas sozinha pra mim, está sendo bem cansativo. Na primeira parte foi,
mas, agora, até na questão de submeter ao comitê de ética eu dependo do orientador. Então,
não vai dar para ficar empurrando as coisas com a barriga o tempo todo. (Relato da
primeira autora).

Essa fala foi o conteúdo do áudio que enviei ao coordenador adjunto do curso. Após acolher as recorrentes indignações e perceber o quanto aquilo estava me afetando psicologicamente, o coordenador se posicionou para que pudéssemos conversar. Ele reiterou a importância da pesquisa realizada por mim, bem como a compreensão acerca da minha angústia, já que, segundo ele, "tudo de errado que poderia acontecer com um estudante no programa de Mestrado, aconteceu comigo". Ainda assim, ele se prontificou a marcar uma reunião com uma professora que estava ingressando no programa, para que pudéssemos alinhar a possibilidade de dar início ao processo de orientação. Uma mistura de tensão e alegria tomou conta de mim. Aceitei, aguardei e agradeci.

Em uma terça-feira, 28 de julho de 2020, quando já deveria defender a dissertação, lá estava eu, conhecendo uma possível orientadora. Já não havia muitas expectativas acerca da relação humana a ser construída! O que eu queria era encontrar uma profissional que fizesse o seu trabalho e me permitisse fazer o meu; afinal, até ali, tudo que tinha feito estava a carecer da figura de um/a orientador/a. Sim! Eu estava sendo racional e carregava comigo o desencanto que as vivências no Mestrado me trouxeram. Ao mesmo tempo, porém, de maneira ancestral ${ }^{8}$, reconhecia que a terçafeira é dia de caminho e direção - ouvi isso minha vida inteira! De certa forma, esperançava uma melhora.

No horário combinado, estávamos em uma sala virtual, eu, a professora e o coordenador adjunto, para iniciar a conversa. O coordenador Marcelo Diniz fez uma breve apresentação dos motivos que nos levaram a estar ali e cedeu espaço para que a professora se apresentasse. Silenciei, aguardando a costumeira chuva de certificações e qualificações que os acadêmicos utilizam para

\footnotetext{
8 Acolhemos aqui o conceito de ancestralidade/ancestral a partir da cosmovisão africana que significa visão de circularidade sobre o mundo, bem como "chão" onde enterramos os nossos mortos e de onde buscamos nosso alimento vivo e espiritual (PETIT, 2015).
} 
dizer quem são. Fui surpreendida com um sorriso acolhedor, um olhar sensível e uma fala breve, que, naquele momento, resumiam o caminho da Doutora Mariana Fernandes dos Santos, alguém que estava ali para me conhecer, me escutar e me ajudar. Já estava sendo diferente de tudo que tinha vivido até então. Respirei, compartilhei a tela com o slide da qualificação e apresentei toda a pesquisa, de maneira resumida, finalizando com um "é isso, preciso de alguém para me orientar"! Foi impossível conter a emoção.

Do outro lado da tela, Mariana abraçou a minha pesquisa, a minha ideia e a minha história - que, segundo ela mesma, em muito se assemelhava com a dela. O professor Marcelo repetia inúmeras vezes: "Acho que vocês vão caminhar muito bem juntas! A professora Mariana é uma referência e competente pesquisadora da temática que você está estudando, e, além disso, é uma mulher negra". E eu só conseguia agradecer ao divino por ter me permitido aguentar, resistir até ali. Meu problema nunca foi escrever! Inclusive porque a escolha da temática sempre teve uma implicação pessoal. O fato é que escrever sozinha, sem orientação, não garante a finalização da pesquisa como de fato deva ser. Naquele dia, vi a possibilidade de seguir e conseguir. Não renascia, reexistia na qualidade de mestranda e pesquisadora. Era o início de uma nova caminhada.

No mesmo dia, trocamos endereços de e-mails e programamos a escrita dos termos que solicitariam o aumento do prazo para a defesa e marcamos um encontro para a orientação. Sim! No mesmo dia. E, nesse primeiro encontro, muita coisa fluiu! Inclusive o fato de que, por mais que Mariana conhecesse o meu trabalho de Mestrado, ela queria também me conhecer. Imagine a estranheza que isso me causou, já que, até ali, a relação de orientação que vivenciei tinha sido totalmente desmotivadora.

Daí surgiu a necessidade de falar de mim - coisa que eu sempre tive muita dificuldade e que aparecia como questionamento em diversas fases da minha vida acadêmica, como mostra uma das fichas de avaliação que me entregaram preenchida na qualificação - "traga as experiências da Bianca de Refrigeração". O que a estudante não sabia, ao escrever essa sugestão na ficha, era que as vivências da "Bianca de Refrigeração" estavam propositalmente amontoadas junto a diversas dores que a trajetória de vida me trouxe, e tudo que eu não queria era revisitar aquele lugar. Nenhuma fase de escrita nesta pesquisa foi tão cansativa quanto essa. Entretanto, diferentemente de todas as outras etapas, eu pude perceber que, para além do divino, eu não estava só, minha orientadora estava comigo!

\begin{abstract}
Bianca (Bia) chegou em minha vida em momento bem difícil pessoalmente e ainda em meio a uma pandemia (2020), foi um encontro importante para mim, me fez reiniciar em relação a várias situações que eu estava desestimulada. Ela apresentou um material denso, com robustez teórica que demonstrava a dedicação e responsabilidade dela, mas também os excessos de uma escrita que pesava as dores e angústias que ela trazia. Fiz algumas ponderações inicialmente sobre algumas necessidades de redimensionamento metodológico e teórico, mas o meu foco principal era acolher e abraçar Bia, e, também, me sentir abraçada para que de fato pudéssemos iniciar uma parceria de orientação. (Relato da segunda autora).
\end{abstract}

A relação orientanda/o-orientador/a é, antes de tudo, uma relação humana, situações como as trazidas nos diversos relatos aqui mostram a complexidade da tarefa de orientar, uma vez que se trata de lidar não apenas com mais uma produção escrita acadêmica para avaliação, mas com a vida das/dos orientandas/os e seus projetos existenciais. Uma tese ou uma dissertação exige a convergência de intelecto e energias vitais. Assim sendo, são vidas que excedem a atividade institucional e transcendem o academicismo. Dizemos isso não apenas por confrontar essa ideia, mas, principalmente, por termos vivenciado experiências esvaziadas de respeito e de afetividade ao longo da nossa trajetória acadêmica e ter resistido a partir de um processo humanizado de orientação, quando muitos se viram abandonados e desistiram, situação que quase ocorreu conosco. 
O processo de orientação como estratégia de superação do racismo institucional...

Sim, a orientadora também passou por situações de violências na condição de orientanda no Mestrado e no Doutorado.

Acredito que, diante das violências vivenciadas na Pós-Graduação stricto sensu, não desisti porque fazia questão de lembrar da vivência generosa e competente que tive de orientação na Graduação com a professora Marcilene Sampaio (in memoriam), a quem devo a possibilidade de, naquele momento de situações de fortes dores psicológicas e físicas por conta de situações familiares, ela pegou na minha mão e não soltou. Adupe, Marcilene, que as divindades possam te acolher. (Relato da segunda autora).

É importante ressaltar que nunca consegui escrever/relatar nem mesmo essas poucas linhas acima sobre as situações de violências que vivenciei em orientações que envolviam questões de classe, raça, gênero e xenofobia (a menina que se criou e morava/mora no interior da Bahia, não era vista como alguém capaz). Nesses escritos, rodam trombas d'aguas de misto de dor, mas também do reconhecimento de que é necessário externar as feridas, para que elas se curem ou pelo menos entrem em processo de cicatrização. É preciso seguir!

\section{A orientação como estratégia de superação do racismo institucional: quem tem "orí" tem tudo}

O processo de orientação é determinante na produção acadêmica, embora, no Brasil, seja negligenciado e careça de formação que desenvolva as competências necessárias dos/as professores/as para tal, conforme Costa, Sousa e Silva (2015). Em estudo correlato, Leite Filho e Martins (2006) abordaram a influência da relação orientador/a-orientanda/o no processo de elaboração de teses e dissertações dos Programas de Pós-Graduação em Contabilidade do município de São Paulo. Os relatos evidenciaram insegurança e solidão da/o orientanda/o, em relação ao processo de orientação, ocasionadas, principalmente, pela falta de convívio e distanciamento de seus/suas orientadores/as. Constataram que orientadores/as valorizam características técnicas das/os orientandas/os, enquanto orientandas/os destinam elevada importância para as dimensões pessoais e afetivas no convívio com orientadores/as. Tal contradição reflete diversos dos desencontros que relatamos e vivenciamos ao longo desses processos formativos.

Ainda nesse sentido, Nóbrega (2018) afirma que é possível perceber que, nos Programas de Pós-Graduação, a relação orientador/a-orientanda/o é inexplorada, sendo tratada como elemento não importante para a formação do discente e finalização da dissertação ou da tese. Entretanto, o autor ressalta que a produção de conhecimento e de pesquisa ocorre no próprio contato dos/as envolvidos/as, uma vez que a afetividade está entrelaçada no trabalho científico, assim como em qualquer prática que envolva pessoas. A relação entre orientador/a e orientanda/o é intersubjetiva, pois trata-se de uma relação humana, entre pessoas dotadas de emoções, sentimentos, razão e todas as mazelas inerentes à humanidade. Contudo, cabe ressaltar que essas intersubjetividades se somam a responsabilidades acadêmicas que carecem de cumprimento.

Para definir um quadro de referência para a execução dessas responsabilidades, Halse e Malfroy (2010) afirmam que a orientação envolve processos intelectuais, sociais e contextuais, e se unem às dimensões emocionais, morais e políticas. A dimensão intelectual da orientação está relacionada à vocação do curso, considerando a área de concentração e as linhas de pesquisa que se desdobram em disciplinas obrigatórias e eletivas. O processo de orientação nessa dimensão pode se materializar no cumprimento das disciplinas obrigatórias e eletivas, na participação em grupos de estudo e de pesquisa, em seminários e minicursos, na produção de pesquisas com ou sem o orientador, nas leituras para sua dissertação ou tese, na construção e na apresentação de trabalhos em eventos, bem como publicações em conjunto, entre outras possibilidades. A característica 
decisiva dessa dimensão está relacionada à apropriação de conhecimentos teórico-metodológicos na área do curso, bem como à apropriação de conhecimentos relacionados à natureza e à validade desses conhecimentos.

A dimensão contextual, por sua vez, está vinculada ao ambiente de aprendizagem e, segundo Halse e Malfroy (2010), envolve os aspectos não apenas relacionados à estrutura física, mas também ao ambiente institucional que podem facilitar ou dificultar o seu processo de formação. Nessa dimensão, o papel do/a orientador/a é o de auxiliar o/a futuro/a mestre/a ou doutor/a compreender a dinâmica da estrutura de um Programa de Pós-Graduação, como também conduzilo/a uma imersão no campo de referência da pesquisa. Infelizmente, não pude contar com a parceria do primeiro orientador para isso. Entretanto, com a chegada da orientadora a qual fui encaminhada já prestes a desistir do curso, o meu rumo acadêmico se reorganizou e pude conhecer, de fato, o sentido da palavra orientação.

Em se tratando da dimensão social, é relevante dizer que concerne ao convívio do estudante com os diversos atores do dia a dia do curso, de acordo com Zabalza (2004), a orientação constitui uma característica decisiva dessa dimensão por estar associada à construção de novas redes de relacionamentos em razão das diferentes interações sociais que se iniciam e podem se prolongar e gerar engajamento no decorrer da vida acadêmica.

Nesse sentido, cabe destacar as diferenças dos agentes envolvidos no processo de formação, sobretudo àquelas relacionadas a gênero, classe e raça. Isso porque, tais aspectos podem tornar o cenário da aprendizagem marcado pela necessidade de construção de vínculos sociais, que incluam normas de conduta e delimitação dos papéis sociais envolvidos. Enquanto fui (des)orientada por um homem branco, que desconhecia a maior parte dos termos que tratam de racialidade e de gênero ao longo da minha pesquisa, mas não se colocava no lugar de disponibilidade para compreendêlos, me senti esvaziada de forças para seguir - o que nos leva à necessidade de compreender a dimensão emocional.

Tal dimensão pode se materializar em um ambiente de aprendizagem que gera uma ansiedade associada ao processo de aquisição de conhecimento, bem como de adaptação ao contexto da Pós-Graduação com um conjunto de relações mais ou menos coercitivas, próprias do campo científico, no sentido de Bourdieu (1983), bem como a partir das intersecções de raça, gênero e classe que atravessam qualquer processo formativo, e não é diferente na Educação Profissional e Tecnológica. Em particular, quando me vi implorando para que reconhecessem a relevância da temática que tratava da saúde mental e emocional de estudantes negras na Instituição Federal de Educação, Ciência e Tecnologia da Bahia, percebi que, naquele momento, me tornava também, sujeito da pesquisa. Esses são elementos da vivência da Pós-Graduação que podem provocar, por exemplo, medo, raiva, sofrimento e angústia.

De acordo com Mainhard (2009), a formação acadêmica requer do orientador a capacidade de ouvir, de encorajar o debate, de fornecer retorno contínuo ao estudante, de demonstrar atenção e respeito e de se entusiasmar com o processo de orientação. A priori, no que parecia ser primeira experiência de orientação no Mestrado PROFEPT-IFBA, não encontrei nada disso. Essa realidade também permite refletir acerca da moral e da ética que transcende o processo de formação.

Quanto a isso, Halse e Malfroy (2010) apontam a proposição de uma dimensão moral do processo, e que a característica decisiva dessa dimensão está relacionada à conduta ética no processo de orientação, que entendemos que deva ser tanto da parte do/a professor/a como da/o orientanda/o, naquilo que ela/e faz, quanto na construção de um referencial de moralidade para $\mathrm{o} / \mathrm{a}$ futuro/a mestre/a ou doutor/a. Nessa perspectiva, é relevante o/a professor/a apresentar uma conduta ética que se distancie, por exemplo, de equívocos, inverdades, desencontros propositais e 
O processo de orientação como estratégia de superação do racismo institucional...

irresponsabilidades. Cabe, então, ao/à orientador/a dialogar com suas/seus orientandas/os sobre princípios éticos de pesquisa, de ensino, de exercício profissional.

No que se refere à dimensão política, a atuação do/o orientador/a é de suma importância para a compreensão e o posicionamento crítico, frente às relações de poder dentro do campo acadêmico. Em verdade, os Programas de Pós-Graduação são marcados por jogos de poder, conflitos de interesses e disputas simbólicas (BOURDIEU, 1983).

Em algum momento, esses aspectos políticos alcançam o/a discente, que tem no/a orientador/a sua principal referência de compreensão e vivência de melhores alternativas e benefícios em face das adversidades eventuais. No meu caso, quando optei por utilizar referências contra-hegemônicas ainda não citadas pelo programa de Mestrado, enfrentei uma tentativa de impedimento pautada na necessidade de utilizar obrigatoriamente as bases conceituais "aprovadas" pelas linhas de pesquisa. Utilizar da pedagogia histórico-crítica para realizar análises que se referem à raça, gênero e saúde, é possível, mas é necessário compreender que sozinha tal abordagem não daria conta de aprofundar os estudos. À época, no então orientador, não encontrei nenhum apoio ou auxílio, pois ele não costumava trabalhar com a temática.

Compreendendo que a relação estabelecida durante a orientação tem capacidade de afetar a propensão da/o orientanda/o a continuar sua formação, bem como a se atrelar à qualidade das atividades desenvolvidas ao longo do processo formativo, do encontro com Mariana, aquela que, de fato, me orientou, nasceu uma perspectiva de parceria humana, amorosa e decolonial de orientação. Nessa experiência, foi possível compreender que orientadores/as devem pautar seus processos de orientação a partir de uma perspectiva em que as relações com as/os orientandas/os sejam balizadas pela confiança, pelo respeito acadêmico e, principalmente, humano.

Viana e Veiga (2010) destacam que o sucesso da relação e da produção científica requer que o/a orientador/a e a/o orientanda/o estabeleçam um convívio alicerçado no diálogo, na dedicação, no interesse, na disciplina, na responsabilidade e no compromisso, eu concordo e reitero descrevendo a construção que pude vivenciar com a minha orientadora.

Havia todos os alicerces supracitados, bem como formalidade, burocracia, discordâncias teórico-metodológicas, mas, acima de tudo, havia respeito e cuidado, mas que não precisavam estar expostos em discursos que amontoassem expressões típicas - prezada senhora doutora Mariana Fernandes dos Santos. Era prezada sim! Senhora, doutora e minha orientadora! Em poucas palavras, minha "Ori". Fazendo jus à sabedoria ancestral que aponta Orí como sendo destino, aquele que comanda a sua vida, como afirmou Olocun', em 2012. Para além de um apelido carinhoso, referese à divindade pessoal que, cultuada entre outras, é de fato a mais importante do panteão Yorùbá, pois, seja qual for o empenho de outras divindades em favorecer determinada pessoa, todo e qualquer progresso dependerá sempre do que for sancionado por Orí (significa cabeça, na língua Yoruba), conforme Sàlámi e Ribeiro (2015).

Corroborando Severino (2002), a orientação passou a ser um processo que efetivou uma relação essencialmente educativa, pressupondo um trabalho conjunto em que ambas as partes possam ter enriquecimento recíproco em uma interação dialética, na qual esteja ausente qualquer forma de opressão ou de submissão. Nessa fase de reexistência ${ }^{10}$, o meu ori saudou o dela. As

\footnotetext{
${ }_{9}^{9}$ Príncipe Yorùbá, natural de Òșogbo a viver na Alemanha, de onde dirige a Ibile Faith Society, tendo iniciado inúmeras pessoas em diferentes lugares do mundo, no que chama de "religião tradicional Yorùbá". Entrevistado via Facebook, em 18 de setembro de 2012 .

10 A palavra "reexistência" é um neologismo - emprego de palavras novas, derivadas ou formadas de outras já existentes, com atribuição de novos sentidos a palavras já existentes na língua - realizado por grupos e movimentos sociais que ressignificam a essência, ou substância, de suas ações e de suas identidades. Esse substantivo está relacionado a
}

Práxis Educativa, Ponta Grossa, v. 17, 2219574, p. 1-20, 2022 Disponível em: <https://revistas2.uepg.br/index.php/praxiseducativa $>$ 
nossas histórias se cruzaram. E, certamente, a história dela contribuiu muito para que eu compreendesse a necessidade de confiar no próximo e continuar lutando para que sejamos as mulheres comuns que se tornam rainhas!

Esse encontro me fortaleceu para seguir na empreitada, a fim de que quebremos as correntes que tentam aprisionar nossos sentimentos, nossas vozes, nossa força! Talvez, ela nunca consiga mensurar o quanto foi luz para esse processo! Rogo para que seu ori esteja sempre protegido e para que nunca permita que a maldade do mundo lhe faça questionar a pureza do seu coração! A pureza da sua alma, tão mais experiente que a minha, alimenta as minhas certezas sobre mim. Sobre os meus propósitos, os meus caminhos, as minhas escolhas - inclusive, metodológicas. Dar conta dessa demanda aos cuidados das Deusas e de Mariana é, sem dúvida, uma benção. E isso não quer dizer que ela seja perfeita. Nem quer dizer que eu quero ser! Isso é reconhecer o quanto o mundo precisa de pessoas mais humanas. Eu e meu ori seremos eternamente gratos a Mari, minha Ori.

O processo de orientação de Bianca me fez movimentar a busca de cura em relação a vários adoecimentos, para que assim eu pudesse também contribuir com a cura dela, para que pudéssemos caminhar para outras encruzilhadas, a pesquisa que ela já havia trilhado de maneira tão dedicada. E foi esse movimento de trocas e de criação de tecnologias de curas mútuas que desdobrou em muitas atividades juntas, e, principalmente, na construção afetuosa e complexa de um processo de orientação, que, sem dúvida, foi um encontro ancestral entre duas mulheres negras que queriam contribuir com o programa de Mestrado, com a instituição, a sociedade, mas que também estavam ali para tensionar padrões epistemológicos, teóricos e comportamentais pautados na colonialidade e que se efetivam em epistemicídios, racismo epistêmico e, consequentemente, racismo institucional.

É importante dizer que não foi um processo fácil e nem romantizado; ao contrário, aconteceu com todas as tensões que as relações humanas subjazem, mas, principalmente, sabíamos que era uma relação entre os nossos, entre as nossas, que os nossos oris permitiram e reconheceram. Se Bianca acha que eu fui luz na vida dela, ela foi água de levante de ori na minha vida! Um ebó de caminho!

\section{Fechando por hora essa narrativa}

Quando a mulher negra se movimenta, toda a estrutura da sociedade se movimenta com ela. Angela Davis

Os relatos, os estudos e as narrativas aqui apresentadas são os frutos das movimentações de duas mulheres negras com suas diferenças, discordâncias e afetos que buscaram demonstrar que as dificuldades enfrentadas por orientandas/os no processo de orientação são reais e ocorrem desde o surgimento dos cursos de Mestrado e Doutorado até os dias atuais. Como principais considerações oriundas do longo do processo de formação no Mestrado PROFEPT, é possível citar as descobertas de evidências de que a problemática enfrentada é plural e aparece em diversos relatos de colegas do programa, apesar de ser naturalizada. Além disso, a falta de sistematização e o ambiente de autocracia das instituições de Graduação e Pós-Graduação provocam nas/nos orientandas/os sentimento de insegurança, angústia e solidão. Esses sentimentos também

novas formas de falar sobre, de estudar, de pensar, de realizar, de ser e de vir-a-ser, a partir de uma existência resistente, de uma resistência existente, ou de uma existência que insiste em ser, mesmo diante de situações que nos apontam para a desistência. 
decorrem da falta de contato, da consequente falta de apoio, de direcionamento e de retorno dos/as orientadores/as.

No lugar de orientadora, é preciso dizer que escritas como essas são gatilhos de memórias de dor diante das situações que vivenciei no Mestrado e no Doutorado no processo de orientação, mas também é uma oportunidade de cura a partir de narrativas e teorizações, prática que aprendi nas vivências cotidianas e que hooks (2013) entende como um meio de cura para as dores e as violências provocadas pelos racismos, pelo sexismo e pela dominação de classe.

Conforme defendido ao longo do texto, a orientação acadêmica envolve um conjunto de dimensões que estão imbricadas. Embora não haja intenção de determinar um perfil detalhado do/da professor/a orientador/a, a caracterização do que ocorre no processo de orientação acadêmica e como as ocorrências se refletem na vida dos/das estudantes possibilita uma construção de referencial acerca do que "não ser" e "não fazer". A condição de orientador/a não deve ser usada para institucionalizar uma relação de dominação, em que a/o orientanda/o passe a ser submissa/o e se torne refém das cobranças que não estejam envolvidas diretamente no processo de formação. Entretanto, entendemos também que há muitos equívocos de postura por parte de orientandas/os, fato que deve também ser considerado no processo formativo que é a orientação, é preciso o mínimo de empatia para que as relações sejam saudáveis e de relevante qualidade acadêmica.

De modo geral, é possível perceber que a qualidade do trabalho acadêmico se relaciona com a parceria estabelecida entre orientador/a e orientanda/o, e entendemos que uma dissertação ou tese é um trabalho coletivo do/a orientador/a e da/o orientanda/o. A prática do processo de orientação deve ser multifacetada, considerando os elementos intelectuais, contextuais, sociais, emocionais, morais e políticos que se interseccionam e integram a relação entre as pessoas envolvidas. Nesse sentido, a discussão sobre como os processos acadêmicos são responsáveis por gerar ansiedade, depressão e conflitos psicológicos que interferem fortemente na autoestima do/a estudante reitera-se à indicação de que todo o processo de formação é vivencial. Assim sendo, é importante compreendermos que seja a partir das experiências diárias nas aulas, no relacionamento com professores/as, com colegas, com coordenadores/as e com o/a orientador/a, seja na realização de atividades de pesquisa de campo, ou, ainda, no processo de apropriação de discursos acadêmicos, do mesmo modo que trajetórias formativas promovem dores e sofrimentos, elas também são capazes de propiciar caminhadas pautadas na escutatória, no respeito mútuo, no autoamor e na sabedoria ancestral.

Em tempo, ratificamos a importância de mobilizarmos dizeres e saberes para além do conhecimento técnico ou de formações continuadas para qualificar profissionais universitários. Trata-se de um feito que só se materializará a partir de reflexões acerca das (des)aprendizagens, e, por conseguinte, tomadas pelas palavras de hooks (2013), do reconhecimento da necessidade de renovar as práxis de vida, na perspectiva da decolonialidade. O nosso movimento aqui tem intenções estruturais porque esperamos que a sociedade e a comunidade acadêmica e científica, em geral, compreendam e façam os movimentos aqui propostos junto conosco.

\section{Referências}

ALVES, V. M.; ESPÍNDOLA, I. C. P.; BIANCHETTI, L. A relação orientador-orientando na pósgraduação stricto sensu no Brasil: a autonomia dos discentes em discussão. Revista Educação em Questão, Natal, v. 43, n. 29, p. 135-156, maio/ago. 2012. DOI: https://doi.org/10.26512/lc.v14i26.3430 
BERNDT, A. A questão da orientação na pós-graduação em Administração. 2003. Disponível em http://www.forvm.org.br/educarnav.html. Acesso em: 18 ago. 2018.

BOURDIEU, P. O campo científico. In: ORTIZ, R. (org.). Sociologia. São Paulo: Ática, 1983. p. 122-155.

BRASIL. Decreto $\mathbf{N}^{\mathbf{0}} \mathbf{7 . 5 6 6}$, de 23 de setembro de 1909. Rio de Janeiro, 1909. Créa nas capitaes dos Estados da Escolas de Aprendizes Artífices, para o ensino profissional primario e gratuito. Brasília: Câmara dos Deputados, [1909]. Disponível em: https://www2.camara.leg.br/legin/fed/decret/1900-1909/decreto-7566-23-setembro-1909-

525411-publicacaooriginal-1-pe.html. Acesso em: 15 jan. 2022.

CARNEIRO, A. S. A construção do outro como não-ser como fundamento do ser. 2005. Tese (Doutorado em Educação) - Universidade de São Paulo, São Paulo, 2005.

CHIAVENATO, J. J. O Negro no Brasil. São Paulo: Brasiliense, 1986.

CLARK, R. et al. Racism as a stressor for African Americans: a biopsychosocial model. American Psychologist, Washington, v. 54, n. 10, p. 805-816. 1999. DOI: https://doi.org/10.1037/0003$\underline{066 x .54 .10 .805}$

COELHO, F. Relatos selvagens: a margem do sujeito acadêmico, trajetórias e resistências. In: BRAGA, L. A. et al. (org.). O sujeito acadêmico: descolonização do conhecimento?. Campinas: Pontes, 2019. p. 47-65.

COSTA, E. V. A Abolição. São Paulo: Global Editora, 1986.

COSTA, F. J.; SOUSA, S. C. T.; SILVA, A. B. Um modelo para o processo de orientação na pósgraduação. Revista Brasileira de Pós-Graduação, Brasília, v. 11, n. 2, p. 823 - 852, mar. 2015. DOI: https://doi.org/10.21713/2358-2332.2014.v11.638

EVARISTO, C. A Escrevivência e seus subtextos. In: DUARTE, C. L; NUNES, I. R. (org.). Escrevivência: a escrita de nós. Reflexões sobre a obra de Conceição Evaristo. Ilustrações Goya Lopes. Rio de Janeiro: Mina Comunicação e Arte, 2020. p. 26-47.

FREITAS, M. E. Viver a tese é preciso! In: BIANCHETTI, L.; MACHADO, A.M.N. (org.). A bússola do escrever: desafios e estratégias na orientação e escrita de teses e dissertações. 3. ed. São Paulo: Cortez, 2012. p. 223-242.

HALSE, C.; MALFROY, J. Retheorizing doctoral supervision as professional work. Studies in Higher Education, Londres, v. 35, n. 1, p. 79-92, 2010. DOI: https://doi.org/10.1080/03075070902906798

HOOKS, B. Ensinando a transgredir: a educação como prática da liberdade. Tradução Marcelo Brandão Cipolla. 2. ed. São Paulo: WMF Martins Fontes, 2013.

JESUS, C. M. Quarto de despejo: diário de uma favelada. São Paulo: Ática, 2014.

LEITE FILHO, G. A.; MARTINS, G. A. Relação orientador-orientando e suas influências na elaboração de teses e dissertações. Revista de Administração de Empresas, São Paulo, v. 46, p. 99-109, dez. 2006. DOI: https://doi.org/10.1590/S0034-75902006000500008 
LIMA, M.; VALLA, J. As novas formas de expressão do preconceito e do racismo. Estudos de Psicologia, Natal, v. 9, n. 3, p. 401-412, dez. 2004. DOI: https://doi.org/10.1590/S1413294X2004000300002

MAINHARD, T. et al. A model for the supervisor-doctoral student relationship. Higher Education, [s. l.], v. 58, n. 3, p. 359-373, fev. 2009. DOI: https://doi.org/10.1007/s10734-009$\underline{9199-8}$

NÓBREGA, M. H. Orientandos e orientadores no século XXI: Desafios da pósgraduação. Educação \& Realidade, Porto Alegre, v. 43, n. 3, p. 1055-1076, abr. 2018. DOI: https://doi.org/10.1590/2175-623674407.

NOGUEIRA, O. Preconceito racial de marca e preconceito racial de origem: sugestão de um quadro de referência para a interpretação do material sobre relações raciais no Brasil. Tempo Social, São Paulo, v. 19, n. 1, p. 287-308, jun. 2006. DOI: https://doi.org/10.1590/S010320702007000100015.

PETIT, S. H. Pretagogia: pertencimento, corpo-dança afroancestral e tradição oral contribuições do legado africano para a implementação da Lei 10.639/03. Fortaleza: EdUECE, 2015.

SÀLÁMI, S.; RIBEIRO, R. I. Exu e a Ordem do Universo. São Paulo: Oduduwa, 2015.

SANTOS, D. Sete atos oficiais que decretaram a marginalização do povo no Brasil. 2005. Disponível em: http://www.educafro.org.br/site/wp-content/uploads/2021/01/EDUCAFROprova-de-cidadania-tema7-marginalizacao-do-povo-negro.pdf . Acesso em: 15 jan. 2022.

SEGRE, M.; SILVA, F. L. e; SCHRAMM, F. R. O contexto histórico, semântico e filosófico do princípio de autonomia. Revista Bioética, Brasília, v. 6, n. 1, p. 1-9, 1998.

SEVERINO, A. J. Metodologia do trabalho científico. 22. ed. São Paulo: Cortez, 2002.

VIANA, C. M. Q. Q.; VEIGA, I. P. A. O diálogo acadêmico entre orientadores e orientandos. Educação, Porto Alegre, v. 33, n. 3, p. 222-226, jan. 2010.

ZABALZA, M. A. O ensino universitário: seu cenário e seus protagonistas. Porto Alegre: Artmed, 2004.

Recebido em 10/08/2021

Versão corrigida recebida em 09/01/2022

Aceito em 10/01/2022

Publicado online em 20/01/2022 